\title{
Reflexões sobre práticas docentes na educação do campo no município de Japeri - Rio de Janeiro
}

\author{
Reflections about teaching practices in rural education in the municipality of \\ Japeri - Rio de Janeiro \\ Amarildo Paes Leme de Mello \\ Mônica Aparecida Del Rio Benevenuto
}

Resumo: A formação docente e as práticas pedagógicas são alguns dos principais fatores no processo ensino-aprendizagem. Quando se trata de educação do campo, a necessidade da formação continuada para esses docentes se torna fundamental. Neste contexto, este artigo busca apresentar uma reflexão sobre a concepção de professoras de uma escola do campo do município de Jarperi/RJ sobre a formação continuada e as práticas docentes resultantes desta formação. Dessa forma, o trabalho se caracterizou em uma pesquisa qualitativa devido às suas especificidades; também documental, por fazer uso de referências publicadas por meios escritos e eletrônicos e, para o levantamento dos dados, a pesquisa de campo, onde foram realizadas entrevistas semiestruturadas com os sujeitos envolvidos. O resultado demonstrou que a professora que tem maior formação acadêmica, busca formação continuada, consegue enxergar a realidade do campo e procura entender as questões locais, numa proposta pedagógica que articula saberes e transcende a sala de aula. A professora com formação de nível Médio não busca uma formação continuada e não se envolve com o contexto vivido pela escola. Sua prática pedagógica reproduz o planejamento da Secretaria de Educação sem articulação com a realidade do campo. Assim, com base nestas práticas docentes distintas em um mesmo contexto, ressalta-se a importância da formação continuada do professor do campo em suas práticas pedagógicas.

Palavras-chave: Práticas docente, educação do campo, formação continuada.

\begin{abstract}
Teacher training and pedagogical practices are one of the main factors in teaching-learning process. When it comes to rural education, the need for continuing education for these teachers become essential. In this context, the this article seeks to present a reflection on the conception of teachers from a rural school in the municipality of Japeri/RJ about continuing education and the teaching practices resulting from this education. Thus, the work was characterized in a qualitative research due to its specificities, also documentary for making use of references published by written and electronic means and, to collect the data, the Field research, where it was carried out semi-structured interviwes with the subjects involved. The result showed that the teacher who has the most academic education, seeks continuing education and can see the reality of the field and seeks to understand local issues, in a pedagogical proposal that articulates Knowledge and transcends the classroom. The teacher with a secondery education does not seek continuing education and is not involved with the context experienced by the school. Its pedagogical practice reproduces the planning of the Department of Education without articulation with the reality of the Field. Thus, based on these different teaching practices in the same context, the importance of continuing education for rural teachers in their pedagogical practices is enphasized.
\end{abstract}

Key-words: Teaching practices, Field education, continuing education. 


\section{Introdução}

A formação docente e as práticas pedagógicas tem sido tema de estudo muito discutido na atualidade, principalmente pelo fato da tão almejada e necessária melhoria na qualidade de ensino. Nesse sentido, tanto a formação inicial quanto a formação continuada surgem como protagonistas neste processo na busca do desenvolvimento de práticas docentes que promovam a melhoria da qualidade de ensino nas escolas do campo, não se furtando da importância das especificidades desta realidade que agregam valores ao desempenho das práticas pedagógicas.

Neste contexto, este artigo, que é parte de pesquisa de dissertação em andamento, do Mestrado em Educação Agrícola no Programa de PósGraduação em Educação Agrícola da Universidade Federal Rural do Rio de Janeiro - PPGEA/UFRRJ, foca atenção para reflexão sobre a concepção de professoras de uma escola do campo do município de Jarperi/RJ sobre a formação continuada e as práticas docentes resultante desta formação. Sendo assim, foi utilizado como objeto de análise, as experiências docentes e as práticas pedagógicas das professoras da Escola Municipal Carlos Alberto dos Santos Pereira, do município de Japeri/ Rio de Janeiro.

Esse artigo não busca aqui esgotar o debate sobre a formação dos professores das escolas do campo e as práticas docentes e sim contribuir para que este tema se desdobre em outras pesquisas mantendo, assim, o diálogo sobre o assunto. Desse modo, podemos sinalizar para os agentes públicos uma reflexão que possibilite melhoria para a prática docente e para educação do povo do campo oportunizando o exercício pleno da cidadania do povo do campo.

\section{Um breve panorama da Educação do Campo no município de Japeri/RJ}

O município de Japeri localiza-se na região metropolitana do estado do Rio de Janeiro, faz parte da Baixada Fluminense e está a uma distância de $70 \mathrm{Km}$ da capital do Estado. Com cerca de $70 \%$ de seu território composto por área rural, o município possui 31 bairros e uma população estimada em 2017 pelo 
IBGE1 em 101.237 habitantes e só foi elevado à condição de município em dezembro de 1991 através da lei estadual n¹902.

A educação pública municipal de Japeri, representada pela SEMED Secretaria Municipal de Educação, é responsável pela Educação Básica (Educação infantil e Ensino Fundamental) no sistema municipal de educação e tem sob a sua gestão trinta e quatro escolas, sendo que de acordo com a sua localização geográfica, oito delas estão situadas em zona rural e classificadas como escolas do campo pelo IBGE, enquanto vinte e seis estão situadas em zonas urbanas. Segundo a Secretaria Municipal de Educação de Japeri, uma das escolas do campo, Escola Municipal Teófilo Cunha, não é classificada pelo IBGE como Escola do Campo devido estar localizada próxima a uma via pavimentada, porém a SEMED Ihe confere tal classificação por contemplar um público predominantemente campesino e estar em uma área rural. $A$ inclusão desta escola na classificação de escola do campo pela SEMED está em consonância com a resolução n.1 de 03 de abril de 2002 do Conselho Nacional de Educação (CNE) que trata das diretrizes operacionais para a educação básica nas escolas do campo concebe a identidade das escolas do campo da seguinte forma.

\begin{abstract}
A identidade da escola do campo é definida pela sua vinculação às questões inerentes a sua realidade, ancorando-se na sua temporalidade e saberes próprios dos estudantes, na memória coletiva que sinaliza futuros, na rede de Ciências e Tecnologia disponível na Sociedade e Movimentos Sociais em defesa dos projetos que associem as soluções por essas questões à qualidade social da vida coletiva no país. (MEC, 2002, p. 37).
\end{abstract}

Nesse sentido, a identidade da escola do campo vai além da localização geográfica e vários outros fatores e as especificidades do campo devem ser considerados.

Embora o município de Japeri tenha um número considerável de escolas, apenas três escolas oferecem a Educação de Jovens e Adultos, EJA, mas nenhuma das Escolas do Campo é contemplada com a modalidade. Essa modalidade de ensino se torna muito importante para o povo do campo à medida que a vulnerabilidade, no que tange o acesso à educação e consequentemente

\footnotetext{
${ }^{1}$ IBGE - Instituto Nacional de Geografia e Estatística
} 
eleva o número de analfabetismo no campo, é muito presente e grande parte dos jovens e adultos precisam estar presentes nas atividades do campo durante o dia. Bortolotti (2011) destaca a questão do adulto que além de trabalhar, precisa se deslocar por uma longa distância para chegar até a escola,

teriam que, uma longa jornada de trabalho, se deslocar para a cidade mais próxima e assim poder frequentar a escola? Para aqueles que não conhecem a realidade desse universo rural, podem concluir que essa questão é totalmente irrelevante, acabando por reduzi-la e negar o debate sobre o assunto. E se o debate não for estabelecido, já se teria instalada uma situação de opressão e/ou negação do diretito de um povo, uma classe, localidade, etc. (BORTOLOTTI, 2011, p.6).

Nesse contexto podemos dizer que a EJA no campo não é apenas uma questão de educação é também uma questão de inclusão social. É uma questão de cidadania oferecendo uma formação para que torne o povo do campo crítico socialmente e autônomo. Sendo assim, a SEMED deve cumprir com o compromisso político-social da oferta dessa modalidade de ensino nas escolas do campo, de modo a contemplar uma população que não teve e não tem a oportunidade de realizar os seus estudos devido a diversas barreiras, como a longa jornada de trabalho durante o dia, distância da escola, dentre outras que Ihes são impostas.

A Secretaria Municipal de Educação de Japeri está organizada em onze departamentos/setores e dentre eles está o setor de Coordenação da Educação do Campo, subordinada ao Departamento de Coordenação Pedagógica. A coordenação da Educação do Campo surgiu em 2011, no período em que o município de Japeri aderiu ao Programa Escola Ativa, que teve as suas atividades encerradas no final do ano de 2013. Porém, com a participação do município na capacitação dos professores das escolas do campo no Programa Escola da Terra, uma parceria entre a Universidade Federal Rural do Rio de Janeiro com algumas prefeituras do Estado do Rio de Janeiro, no final de 2018, foi recriado o setor de Coordenação da Educação do Campo.

Com a recriação deste setor, o município de Japeri volta a ter um olhar mais atencioso para a Educação do Campo, à medida que recria um setor onde trata especificamente das questões da educação e, do povo do campo do 
município, fazendo-se mais presente com visitas nas escolas, com o objetivo de se informar sobre o desenvolvimento das práticas pedagógicas e também, realizando encontros com os professores para apresentar o que foi a capacitação do Programa Escola da Terra, uma vez que nem todos os professores foram contemplados com a capacitação do programa.

Apesar da recriação do setor de Coordenação da Educação do Campo, ainda não há o tratamento distinto nas orientações e planejamento pedagógico que atenda as escolas do campo, respeitando as suas especificidades, pois, estas ainda seguem com as orientações e planejamento único, direcionados às escolas urbanas, delegando o esforço de adaptação para iniciativas individuais dos professores e, desobrigando o poder público municipal deste compromisso.

\section{A formação dos professores e as Escolas do Campo}

As escolas do campo sempre tiveram carência de professores com formação acadêmica, concomitante com a vivência da realidade do campo, criando assim, uma lacuna entre o que deve ser ensinado e o que deve ser aprendido. Sendo assim, Tardif (2006) apresenta a necessidade de aproximar a experiência individual e coletiva do docente para a construção dos saberes do professor. Para este autor, estes saberes se moldam às experiências individuais e coletivas e, se transforma em hábitos e habilidades de saber, saber fazer e saber ser.

De acordo com a Lei de Diretrizes e Bases 9394/96², em seu artigo 62, para o professor atuar no magistério na educação infantil e nos cinco primeiros anos do ensino fundamental, a exigência de formação mínima é o curso na modalidade Normal oferecido em nível Médio:

A formação de docentes para atuar na educação básica far-seà em nível superior, em curso de licenciatura, de graduação plena, em universidades e institutos superiores de educação, admitida, como formação mínima para o exercício do magistério na educação infantil e nas quatro primeiras séries do ensino fundamental, a oferecida em nível médio, na modalidade Normal. (LDB 9394/96, 1996).

\footnotetext{
2 LDB 9394/96 - Lei de Diretrizes e Bases da Educação Nacional n. 9.394 de 20 de dezembro de 1996.
} 
Sendo assim, esses professores com a formação rasa não tem, em sua maioria ou até mesmo em sua totalidade, o conhecimento sobre o que seja uma classe multisseriada, que se constitui por turmas que são organizadas com alunos de diversas séries (nível de escolarização) e diferentes idades em um mesmo espaço (salas) sob a responsabilidade de um mesmo professor, como destacam Fagundes e Martini (2003). Vale destacar que este não é um modelo de turma que se vê nas escolas urbanocêntricas, inclusive nem todas as escolas do campo são multisséries, porém esta é uma realidade presente na maioria das escolas do campo em Japeri, como as E.M. Carlos Alberto dos Santos Pereira e a E. M. Tânia Mara da Silva Carnaval Basílio que fazem parte deste artigo.

Desse modo, Tardif (1991) ao mesmo tempo em que afirma que o professor já possui uma bagagem, questiona se esse conhecimento trazido pelo professor é todo o saber que precisa para atender satisfatoriamente os discentes. Se tratando de um público do campo este questionamento se torna mais evidente na necessidade de uma formação continuada, pois através dela que serão adquiridos saberes que irão complementar aqueles já conquistados e trazidos pelos professores.

O docente que vai trabalhar em uma escola do campo, primeiramente, precisa entender a grande importância que existe em conhecer a proposta de Educação do Campo, para que possa convergir os seus saberes com os saberes produzidos pelo campo. Caldart (2012) apresenta a identidade deste modelo de educação:

A Educação do Campo nasceu como mobilização/pressão de movimentos sociais por uma política educacional para comunidades camponesas; nasceu da combinação da luta dos Sem Terra pela implantação de escolas públicas nas áreas de Reforma Agrária com as lutas de resistência de inúmeras organizações e comunidades camponesas para não perder as suas escolas, suas experiências de educação, suas comunidades, seu território, sua identidade. (CALDART, 2012, p.15).

É com essa identidade que a educação do campo surge, trazendo elementos culturais, vivências e, juntamente com a dinâmica do campo, um novo modelo de educação, saberes necessários para o bom desempenho do docente nas escolas do campo e consequentemente uma nova forma de se olhar uma 
escola. Nesta linha argumentativa, Tardif (1991) acrescenta que o professor padrão seria aquele que deve conhecer a sua matéria, sua disciplina e seu programa, possuir certos conhecimentos das ciências da educação e pedagogia, mas não deixar de incluir tudo aquilo que assimilou com a prática, com as suas experiências vividas no cotidiano com os seus alunos. Este argumento se remete, necessariamente, a uma formação continuada, mesmo que não sendo adquirida na academia, mas no chão da escola.

Seguindo esta linha de pensamento, para Caldart, "escola é mais do que escola", pois a escola é formadora de opinião e é através dela que o discente sai do estado da escuridão e passa a enxergar mais claramente o que acontece ao seu redor. Nas palavras da autora:

Eu nunca me esqueço de uma frase linda do educador, alfabetizador, um camponês sem terra, de um assentamento enorme no Rio Grande do Sul aonde eu fui: um dia pela força de nosso trabalho e de nossa luta, cortamos os arames farpados do latifúndio e entramos nele. Mas quando nele chegamos, descobrimos que existiam outros arames farpados, como o arame da nossa ignorância, e então ali eu percebi melhor ainda naquele dia, que quanto mais ignorante, quanto mais inocentes diante do mundo, tanto melhor para os donos do mundo, e quanto mais sabido, no sentido de conhecer, tanto mais medrosos ficarão os donos do mundo. (CALDART, 2000, p.172)

Conhecer implica um movimento recíproco entre os educadores, educando e demais sujeitos envolvidos com o ato de educar. Implica também em ir além das demandas da escola tradicional e conservadora, pois o conhecimento emancipador não pode ser baseado apenas em mera exposição de conteúdos, lições e exercícios de fixação, esse conhecimento tem que ser produzido através do coletivo e não na individualidade e interesse de alguns. Vale destacar a reflexão que Arroyo e Fernandes (1999) fazem sobre as políticas educacionais em âmbito nacional bem como o termo "educação do campo":

Há no campo um expressivo movimento pedagógico, com experiências escolares inovadoras coladas às raízes populares, às matrizes culturais do povo do campo. A educação escolar ultrapassa a fase "rural", da educação escolar "no" campo e passa a ser "do" campo. Está vinculada a um projeto democrático popular de Brasil e de Campo. Realiza-se uma relação visceral entre as mudanças na educação e os ideais do Movimento/ Social. Vai-se, portanto, além da "escolinha de 
letras" (ler, escrever e contar) para se trabalhar participativa e criativamente um projeto de Brasil, um projeto de Campo, resgatando e valorizando os valores culturais típicos do povo do Campo. Há uma mobilização local, regional e nacional procurando garantir uma "educação básica do campo", portanto, com novos conteúdos, novos processos pedagógicos, novo enfoque na tarefa dos professores, das professoras, das famílias, da comunidade e dos próprios educandos. (ARROYO; FENANDES, 1999, p.6)

Complementando e sustentando este argumento, Bicalho (2018) ressalta que a política educacional até então destinada ao campo considerava esse espaço a extensão da cidade de modo que a instituição escolar, currículos, histórias, identidades e memórias dos educadores foram constantemente ignorados e a produção dos saberes partia dos centros urbanos para o campo.

Diante deste contexto e com o aparecimento das escolas do campo, surgiu também uma nova forma de fazer pedagógico, onde vários ajustes tiveram de ser feitos para atender de forma qualitativa esse público do campo. A LDB 9394/96 - Lei de Diretrizes e Bases da Educação, em seu artigo 28, diz:

$\mathrm{Na}$ oferta de uma educação básica para a educação rural, os sistemas de ensino promoverão as adaptações necessárias a sua adequação as peculiaridades da vida rural e de cada região, especialmente: I - Conteúdos curriculares e metodologias apropriadas as reais necessidades e interesses dos alunos da zona rural; II - Organização escolar própria, incluindo adequação do calendário escolar às fases do ciclo agrícola e as condições climáticas; III - adequação a natureza do trabalho na zona rural. (Brasil, 1996, art.28).

Surgiu não só a organização curricular e estrutural, mas houve também, ou melhor, há a necessidade de profissionais capacitados para desenvolverem as atividades desse modelo de educação. Assim, relata Molina (2012), que não é só da infraestrutura, do acesso e também da formação que a educação do campo precisa. Para a autora existem outros fatores que precisam ser contemplados no ensino rural. A cultura, o saber local e a forma de produção das comunidades em que essas escolas estão inseridas são alguns fatores que devem receber também uma boa atenção, não se limitando apenas em um padrão de saber universalizado pelas instituições.

Molina vai além em sua argumentação sobre a organização curricular das graduações em educação do campo, em especial a Licenciatura em Educação 
do Campo (LEC), ressaltando a busca por atitudes e processos que venham a exigir uma sinergia entre teoria e prática respeitando a bagagem social e cultural trazidas pelos estudantes.

A Licenciatura em Educação do Campo é um curso direcionado a formação docente para aqueles que desejam atuar nos anos finais do ensino fundamental e no ensino médio das escolas do campo. A LEC/UFRRJ 3 é oferecida na modalidade presencial e em regime de alternância, o que possibilita uma melhor condição de oferta de ensino superior para a população do campo que deseja ingressar em um curso superior. $O$ regime de alternância se divide em dois tempos educativos: o tempo escola/universidade (TE) e o tempo comunidade (TC), no qual o estudante vivencia o que aprendeu na academia nos acontecimentos na comunidade. Então, esse estudante não se forma em uma disciplina específica, mas sim em umas das grandes áreas do conhecimento. No caso da LEC/UFRRJ, se formam em Ciências Sociais e Humanas (Sociologia e História).

A importância de uma formação ampliada para o professor do campo é também reforçada por Arroyo (2004), ao ressaltar que se deve direcionar todos os esforços para que a população do campo tenha acesso ao conhecimento e produza saberes, e que apenas as habilidades com a língua portuguesa e a matemática não sejam suficientes para a sua formação plena como cidadão.

\section{A caminho das escolas do campo: o percurso da pesquisa}

Para atender aos objetivos deste estudo, foi realizada uma abordagem qualitativa, pois a pesquisa não se preocupou com a representatividade numérica, mas sim, com o aprofundamento da compreensão de um grupo social, de uma organização (MINAYO, 2001). Para compreender melhor a abordagem qualitativa Michel (2015, p.40) afirma que "o ambiente da vida real é a fonte direta para a obtenção de dados, e a capacidade do pesquisador de interpretar esta realidade". Nesta perspectiva, Marconi e Lakatos (2007, p.185) destacam que "a pesquisa bibliográfica, ou de fontes secundárias, abrange toda a bibliografia já

\footnotetext{
${ }^{3}$ LEC/UFRRJ - Licenciatura em Educação do Campo da Universidade Federal Rural do Rio de Janeiro
} 
tornada pública em relação ao tema de estudo, desde publicações avulsas, boletins, jornais, revistas, livros, pesquisas, monografias, teses, material cartográfico“.

A pesquisa também foi documental, sendo consultados documentos oficiais. Como procedimento para o levantamento e coleta dos dados foi realizada pesquisa de campo no qual foram utilizadas entrevistas semiestruturadas. Foram contactadas duas escolas do campo do município com a participação de dois professores, duas gestoras no período de fevereiro a maio de 2020. Após o levantamento e coleta dos dados foi realizada uma análise em relação ao tema em foco possibilitando uma reflexão sobre a pesquisa. Neste artigo a ênfase reflexiva será em torno das práticas pedagógicas reveladas por duas professoras da Escola Municipal Carlos Alberto dos Santos Pereira e sua relação com as escolas e a educação do campo.

\section{Práticas docentes nas Escolas do Campo do município de Japeri.}

A necessidade de valorização dos docentes, suas práticas pedagógicas e os espaços menos privilegiados que estes docentes ocupam vem sendo reforçada em vários estudos sobre a Educação do campo. O difícil acesso às escolas, condições de trabalho, salários inferiores, escassez de qualificação profissional, infraestrutura precária são alguns fatores que contribuem para essa pouca valorização (INEP, 2007; RAMOS; MOREIRA; SANTOS, 2004).

Nesse sentido, faz-se necessário conceituar práticas pedagógicas para que se compreenda a importância do seu papel no processo de ensinoaprendizagem, logo Caldeira e Zaidan (2010) assim definem:

A Prática Pedagógica é entendida como uma prática social complexa, acontece em diferentes espaço/tempos da escola, no cotidiano de professores e alunos nela envolvidos e, de modo especial, na sala de aula, mediada pela interação professor- aluno-conhecimento. Nela estão imbricados, simultaneamente, elementos particulares e gerais. Os aspectos particulares dizem respeito: ao docente - sua experiência, sua corporeidade, sua formação, condições de trabalho e escolhas profissionais; aos demais profissionais da escola - suas experiências e formação e, também, suas ações segundo o posto profissional que ocupam; ao discente - sua idade, corporeidade e sua condição sociocultural; ao currículo; ao projeto político-pedagógico da 
escola; ao espaço escolar - suas condições materiais e organização; à comunidade em que a escola se insere e às condições locais (CALDEIRA E ZAIDAN, 2010, p.21).

Iniciaremos a discussão sobre práticas pedagógicas abordando a formação do docente no município de Japeri que, diferentemente de muitos quadros apresentados nas diversas literaturas, apresenta a formação mínima como condição ao exercício do magistério na educação infantil e nos anos iniciais do ensino fundamental, que é o ensino Médio na modalidade Normal, como já apresentado.

Embora a exigência mínima seja o ensino Médio na modalidade Normal, grande parte dos professores que atuam no município de Japeri, nas escolas do campo possui nível superior além de alguns docentes com pós-graduação lato senso.

A formação docente é um fator muito importante para as práticas pedagógicas, pois é através dela que o professor adquire ferramentas e recursos pedagógicos capazes de promover o desenvolvimento do processo ensinoaprendizagem. Ser um fator importante não refuta a necessidade de outros fatores agregarem elementos significativos na aprendizagem dos alunos, pelo contrário, reforça a necessidade de criar um diálogo entre os diversos saberes produzidos no campo, com as particularidades em que a escola está inserida.

Nesse contexto, a formação continuada tem grande relevância no desempenho das práticas docente, conforme Freire (2001) destaca, que

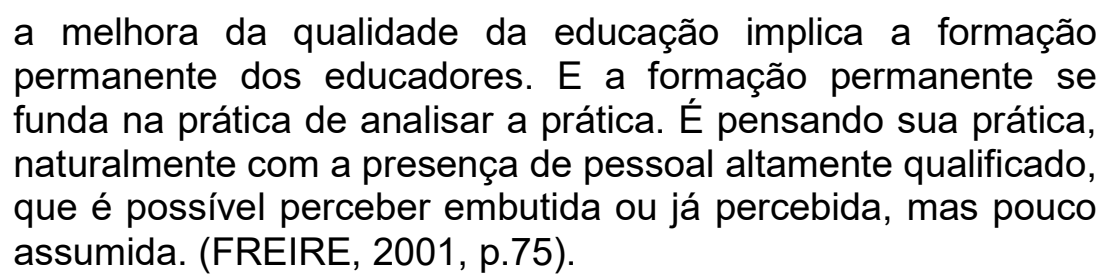

Rever as práticas docentes que estão sendo aplicadas, se configura em um modelo de formação continuada, porém há outras maneiras de possibilitar ao professor uma formação continuada. Política pública direcionada ao desenvolvimento de capacitação docente das escolas do campo pode ser uma dessas possibilidades, de fazer com que o professor reflita sobre a forma na qual 
está desenvolvendo a sua prática pedagógica, ao mesmo tempo em que o coloca diante de outras formas de fazer pedagógico.

Nesse sentido, em 2011, a Secretaria Municipal de Educação do município de Japeri - SEMED, deu um passo importante em direção à educação do campo, ao aderir ao Programa Escola Ativa em parceria com a Universidade Federal Rural do Rio de Janeiro que tinha como proposta, a melhoria da qualidade de ensino das escolas do campo através da formação continuada dos professores e, junto a esta formação, a promessa de melhoria nas infraestruturas destas escolas (SEMED, 2020).

Outro fator muito importante para a prática docente é o espaço onde ocorre a produção dos saberes, onde acontecem as relações, a zona de aproximação, se assim podemos chamar, pois é onde o aluno se aproxima dos diversos elementos que irão dar significados ao seu aprendizado, e no caso da educação do campo se tornam fundamentais. Nesta perspectiva, o campo é um espaço dinâmico com uma variedade de elementos que, a todo o momento se convergem transformando a natureza em fonte de conhecimento, numa proposta pedagógica que se alinha a de Freire (1996, p.25) ao sustentar que "ensinar não é transferir conhecimento, mas criar as possibilidades para a sua produção ou a sua construção".

Sendo assim, as escolas do campo do município de Japeri, possuem estrutura, na sua maioria, seguindo os padrões das escolas urbanas, pois embora sejam classificadas como escolas do campo pelo IBGE, o município não faz distinção entre as escolas do campo e as escolas urbanas no que tange às infraestruturas. Exceto a Escola Municipal Carlos Alberto dos Santos Pereira, as demais escolas do campo possuem prédio próprio, abastecimento de água encanada, luz, esgoto, coleta de lixo, algumas com quadra poliesportiva coberta e laboratório de informática.

A Escola Municipal Carlos Alberto dos Santos Pereira é uma escola do campo diferenciada das demais dentro do sistema de ensino do município de Japeri, no que se refere a infraestrutura e via de acesso. A escola não possui abastecimento de água encanada, a água é oriunda de nascentes próximas a escola, possui energia elétrica, não possui coleta de lixo nem saneamento 
básico. A escola está situada em uma comunidade com uma população de aproximadamente 200 pessoas onde a maioria de seus moradores é formada por trabalhadores rurais autônomos, que não tem sítios próprios e terceirizam sua mão de obra em sítios da região.

A escola atende 18 crianças, atualmente organizados em duas classes multisseriadas, uma turma com 11 alunos que atende a Educação infantil e o $1^{\circ}$ ano do Ensino fundamental e a outra turma com 07 alunos e atende do $2^{\circ}$ ao $5^{\circ}$ ano do Ensino Fundamental. Para atender esta demanda a escola conta com uma estrutura de um pavimento, com duas salas de aula, uma cozinha, dois banheiros, um pequeno espaço coberto como uma espécie de varanda que é utilizado como refeitório para servir a merenda, uma sala que conjuga a secretaria, sala de direção e sala de professores e um pequeno espaço aberto onde são realizadas as atividades de educação física e recreação.

O quadro de funcionários é composto por quatro profissionais: uma gestora, uma subgestora que acumula a função de professora, uma professora e uma cozinheira que acumula função de serviços gerais.

A reflexão realizada sobre a importância da prática docente comprometida com o contexto do campo para além da sala de aula nos leva a analisar o perfil das duas professoras que atuam nesta escola que possuem características bem distintas sobre o papel docente na proposta da educação do campo. A primeira delas, chamaremos de professora 1, é graduada em matemática e possui pósgraduação em letramento e demonstra interesse em sua formação continua, o que a levou à capacitação do Programa Escola Ativa e ao Programa Escola da Terra. A professora 2, possui a formação mínima exigida para o cargo, ou seja, o nível Médio na modalidade Normal. Apesar de ter participado da capacitação do Programa Escola Ativa, não chegou a concluir. Da mesma forma, revelou não participar de nenhuma outra formação, seja ela direcionada ao público do campo ou não.

Uma característica marcante na educação do campo é a relação de pertencimento que o docente tem com a escola e com o local em que ela está inserida, o que irá influenciar de forma significativa na sua prática pedagógica. Sendo assim, podemos observar uma grande diferença entre os docentes das 
escolas do campo entre aqueles que vêm para campo e aqueles que são do campo.

A professora 1 não reside em uma região rural, mas trabalha há mais dez anos como professora em escola do campo, nessa mesma escola. Em seu trabalho busca conhecer a realidade local e com isso criou um sentimento de pertencimento ao campo que faz com que as suas práticas pedagógicas articulem o contexto de sala de aula com seu entorno proporcionando interação entre o que se vive e o que se aprende num processo complexo que se retroalimenta conforme proposto por Morin (2007, p.38-39) em sua teoria da complexidade.

[...] de fato, há complexidade quando elementos diferentes são inseparáveis constitutivo do todo (como o econômico, o político, o sociológico, o psicológico, o afetivo, o mitológico), e há um tecido interdependente, interativo e retroativo entre o objeto de conhecimento e seu contexto, as partes e o todo, o todo e as partes, as partes entre si. Por isso a complexidade é a união entre a unidade e a multiplicidade.

Nesse contexto, a professora 1 se considera uma professora do campo pois, além de possuir a dupla função de subgestora e professora, acumula uma vivência do campo e conhecimentos sobre a educação do campo adquirida em cursos de formação continuada como o Programa Escola Ativa, Programa Escola da Terra, entre outros. Sua prática pedagógica é pautada no diálogo entre a experiência docente, articulação entre o planejamento enviado pela Secretaria Municipal de Educação e a cultura local, e suas aulas acontecem dentro e fora da sala de aula, usando o campo como recurso para a produção de conhecimento. Para ela, os cursos de formação continuada e a vivência na escola e o convívio com a comunidade tem sido os elementos que tem construído a sua identidade profissional e é isso que tem motivado cada vez mais seu desejo em trabalhar nesta escola.

Eu estou trabalhando no município há mais de dez anos, vivenciei muitas coisas aqui neste bairro, nesta escola, e mesmo não morando aqui, e sabendo das dificuldades que é trabalhar em uma escola do campo, não quero e nem pretendo sair desta escola, mesmo sabendo que as unidades urbanas tem mais recursos e mais acesso. (PROFESSORA 1) 
A medida que a professora 1 se envolve cada vez mais com as questões da comunidade, da escola e do campo, constrói uma relação de pertencimento e identidade rural. Esta prática pedagógica demonstra atender ás reivindicações dos movimentos do campo por uma educação do campo, que como vimos, tem o sentido de melhorar a qualidade de ensino nas escolas do campo contemplando os saberes produzidos pelos sujeitos do campo a medida que se discute uma educação feita no campo e pensada para o campo respeitando as especificidades existente no campo. É nesse sentido que Kolling, Cerioli \& Caldart (2002) fundamentam o sentido da expressão "Por uma Educação do campo":

Quando dizemos Por Uma Educação do Campo, estamos afirmando a necessidade de duas lutas combinadas: Pela ampliação do direito à educação e a escolarização no campo; e pela construção de uma escola política e pedagogicamente vinculada à história, à cultura e as causas sociais e humanas dos sujeitos do campo, e não um mero apêndice da escola na cidade: uma escola enraizada também na práxis da Educação Popular e da pedagogia do oprimido (KOLLING; CERIOKI \& CALDART, 2002, p. 13).

A professora 2, traz consigo características de professora urbana, suas práticas pedagógicas estão pautadas exclusivamente no planejamento enviado pela SEMED, que não se articula com a realidade das escolas do campo. Consequentemente, suas aulas são realizadas somente em sala de aula, sem o emprego de instrumentos e metodologias pedagógicas, que seriam possibilitadas através de seu envolvimento com espaços de formação continuada e que, além de enriquecer sua atuação docente, a aproximaria da realidade em que atua. Para Caldart (2002), esta conduta pedagógica está próxima da concepção da escola que está no campo que infere apenas o sentido de localização geográfica, indicando que a escola está situada em um espaço rural, apresentando uma educação construída por sujeitos sem raízes com o campo e sem ouvir os sujeitos do campo para saber o que eles desejam, acreditam e querem para os seus filhos. 


\section{Considerações finais}

A formação docente é, indubitavelmente, importante para o desenvolvimento das práticas pedagógicas e quando se fala de educação do campo, a formação continuada ganha um papel de destaque no desempenho das práticas docentes. Pudemos ver claramente essa importância nas duas professoras da Escola Municipal Carlos Alberto dos Santos Pereira - Japeri/RJ, que trabalham na mesma escola, com o planejamento criado pelo mesmo setor, porém possuem práticas pedagógicas distintas dentro do mesmo sistema de ensino. Pudemos perceber claramente a diferença entre estar no campo e ser do campo.

Vale reafirmar que a formação continuada do professor do campo não deve ser uma iniciativa particular, mas promovida pela gestão pública através da SEMED, que deve cumprir com a sua responsabilidade com a educação do campo para além da manutenção da infraestrutura das escolas. Implica compreender esta educação e as escolas como espaço que promovem a construção e a reprodução de saberes e de vida. A formação continuada dos professores é uma via para a construção dessa concepção, que também deve se fazer acompanhar da oferta de condições dignas de trabalho, materiais pedagógicos, entre outras necessidades, que viabilizam a garantia de concretizar o direito a educação de qualidade para o campo.

\section{Referências}

ARROYO, Miguel Gonzalez; CALDART, Roseli Salete; MOLINA, Mônica Castagna. Por uma educação básica do campo. Petrópolis: Vozes, 2004.

ARROYO, Miguel Gonzales e FERNANDES, Bernardo Mançano. A educação básica e o movimento social do campo - Por uma Educação Básica do Campo. Brasília - DF, Coleção Por Uma Educação Básica do Campo, n², 1999.

BICALHO, Ramofly. Reflexões sobre o PROCAMPO - Programa de Apoio à formação Superior. ECCOS - Revista Científica, São Paulo, N.45, p.221-236, 2018.

BORTOLOTTI, F. EJA no Campo: Limitações e Conquistas. Monografia aperfeiçoamento/Especialização em Educação do Campo. Universidade Federal do Paraná. Paraná, 2011. 
BRASIL, Ministério da Educação (MEC). Conselho nacional de educação (CNE). Resolução CNE/CEB n.1, de 3 de abril de 2002. Instituiu diretrizes operacionais para a educação básica nas escolas do campo. Diário Oficial da União, Brasília, 9 de abril de 2002. Seção 1, p. 32.

, MINISTÉRIO DA EDUCAÇÃO. LEI DE DIRETRIES E BASES DA EDUCAÇÃO NACIONAL - LDBEN. Lei n.9394/96, de 20 de dezembro de 1996.

CALDART, Roseli Salete. Pedagogia do movimento sem terra: Escola é mais do que escola. Petrópolis, RJ: Vozes, 2000.

Por uma educação do campo: traços de uma identidade em construção. In: Educação do campo: identidade e políticas públicas- Caderno 4. Brasília: Articulação Nacional "Por Uma Educação Do Campo", 2002.

Educação do Campo. In: Dicionário da educação do campo. CALDART, Roseli Salete; PEREIRA, Isabel Brasil; ALANTEJANO, Paulo; FRIGOTTO, Gaudêncio. (Orgs.). São Paulo: Expressão Popular, 2012.

CALDEIRA, Anna M. S.; ZAIDAN, Samira. Práticas pedagógicas. In: Oliveira, Dalila A.; DUARTE, Adriana C.; VIEIRA Lívia Maria F. (Org.) Dicionário: trabalho, profissão e condição docente. Belo Horizonte: GESTRADO/FAE/UFMG, 2010. V.1.

FAGUNDES, José; MARTINI, Adair Cesar. Políticas educacionais: da escola multisseriada à escola nucleada. Olhar de Professor, Ponta Grossa, v. 6, n. 1, p. 99-118, 2003.

FREIRE, Paulo. Pedagogia da Autonomia: saberes necessários à prática educativa. São Paulo: Paz e Terra, 1996.

Política e Educação: Ensaios. 6ª Ed. São Paulo: Cortez, 2001. (Org. e notas de Ana Maria Araújo Freire).

Instituto Nacional de Estudos e Pesquisas Educacionais Anísio Teixeira (INEP). Panorama da educação do campo. Brasília, DF, 2007.

KOLLING, E. J., CERIOLI, P. R., CALDART, R. S. (Orgs.). Educação do campo: Identidade e Políticas Públicas. Articulação Nacional Por Uma Educação do Campo, Brasília, V.4, 2002.

MARCONI, Marina de Andrade; LAKATOS, Eva Maria. Metodologia do trabalho científico: procedimentos básicos, pesquisa bibliográfica, projeto e relatório, publicações e trabalhos científicos, 6. ed. São Paulo: Atlas S.A., 2007.

MICHEL, M. H. Metodologia e pesquisa científica em ciências sociais. São Paulo: Atlas, 2015.

MINAYO, Maria Célia de Souza (Organizadora); DESLANDES, Suely Ferreira; GOMES, Romeu. Pesquisa social: teoria, método e criatividade. Ed. Vozes Petrópolis, 2001. 
MOLINA, M. C; SÁ, L. M. A Licenciatura em educação do campo da universidade de Brasília: Estratégias Político pedagógicas na formação de educadores do campo. In: Licenciaturas em Educação do Campo - Registros e reflexões a partir das experiências piloto (UFMG; UnB; UFS e UFBA) (Orgs.) Belo Horizonte: Autêntica Editora, 2011.

NOVA ESCOLA; disponível em http://novaescola.org.br/conteudo/970/entrevista-monicamolina-especialistaem-educaçao-do-campo. Acesso em 23 de junho de 2020.

MORIN, E. Os sete saberes necessários à educação do futuro. São Paulo: Cortez; Brasília, DF: UNESCO, 2007.

SEMED; disponível em http://www.semed-novo.semedjaperi.rj.gov.br/. Acesso em 22 de janeiro de 2020.

TARDIF, Maurice. LESSARD, Claude. LAHAYE, Louise. Os professores face ao saber: Um esboço de uma problemática do saber docente. Teoria e Educação. nº4, p.215-233 Porto Alegre, RS, 1991.

Saberes docentes e formação profissional. ( $6^{a}$ Ed.). Petrópolis, Rio de Janeiro: Vozes, 2006.

\section{Sobre os autores}

Amarildo Paes Leme de Mello

amarildo_adm@yahoo.com.br

Mestrando do Programa de Pós-Graduação em Educação Agrícola PPGEA/UFRRJ

\section{Mônica Aparecida Del Rio Benevenuto}

monicadelrio@UFRRJ.br

Professora titular do Instituto de Ciências Sociais Aplicadas da UFRRJ. 